\title{
Bone conduction hearing in the Guinea pig and the effect of artificially induced middle ear lesions
}

Mingduo Zhao, Anders Fridberger and Stefan Stenfelt

The self-archived postprint version of this journal article is available at Linköping University Institutional Repository (DiVA):

http://urn.kb.se/resolve?urn=urn:nbn:se:liu:diva-158924

N.B.: When citing this work, cite the original publication.

Zhao, M., Fridberger, A., Stenfelt, S., (2019), Bone conduction hearing in the Guinea pig and the effect of artificially induced middle ear lesions, Hearing Research, 379, 21-30.

https://doi.org/10.1016/j.heares.2019.04.006

Original publication available at:

https://doi.org/10.1016/j.heares.2019.04.006

Copyright: Elsevier (12 months)

http://www.elsevier.com/

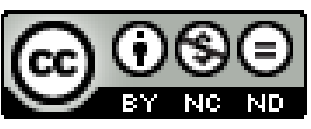




\title{
Bone conduction hearing in the Guinea Pig and the effect of artificially induced middle ear lesions
}

Mingduo Zhao, Anders Fridberger, Stefan Stenfelt

Department of Clinical and Experimental Medicine, Linköping University, 58185 Linköping, Sweden

Corresponding author: Mingduo Zhao, E-mail: mingduo.zhao@liu.se, postal address: Department of Clinical and Experimental Medicine, Technical Audiology, Linköping university, 58185 Linköping, Sweden.

\begin{abstract}
Although human bone conduction (BC) hearing is well investigated, there is a lack of information about $\mathrm{BC}$ hearing in most other species. In humans, the amount of conductive loss is estimated as the difference between the air conduction (AC) and BC thresholds. Similar estimations for animals are difficult since in most species, the normal $\mathrm{BC}$ hearing thresholds have not been established. In the current study, the normal $\mathrm{BC}$ thresholds in the frequency range between $2 \mathrm{kHz}$ and $20 \mathrm{kHz}$ are investigated for the Guinea pig. Also, the effect of a middle ear lesion, here modelled by severing the ossicles (ossicular discontinuity) and gluing the ossicles to the bone (otosclerosis), is investigated for both $\mathrm{AC}$ and $\mathrm{BC}$.

The hearing thresholds in the Guinea pigs were estimated by a regression of the amplitude of the compound action potential (CAP) with stimulation level and was found robust and gave a high resolution of the threshold level. The reference for the $\mathrm{BC}$ thresholds was the cochlear promontory bone velocity. This reference enables comparison of $\mathrm{BC}$ hearing in animals, both intra and inter species, which is independent on the vibrator and stimulation position. The vibration was measured in three orthogonal directions where the dominating vibration directions was in line with the stimulation direction, here the ventral direction. The $\mathrm{BC}$ thresholds lay between -10 and $3 \mathrm{~dB}$ re $1 \mu \mathrm{m} / \mathrm{s}$.

The slopes of CAP growth function were similar for $\mathrm{AC}$ and $\mathrm{BC}$ at low and high frequencies, but slightly lower for $\mathrm{BC}$ than $\mathrm{AC}$ at frequencies between 8 and $16 \mathrm{kHz}$. This was attributed to differences in the stimulus levels used for the slope estimation and not a real difference in CAP slopes between the stimulation modalities. Two kinds of middle ear lesions, ossicular discontinuity and stapes glued to the surrounding bone, gave threshold shifts of between 23 and $53 \mathrm{~dB}$ for $\mathrm{AC}$ while it was below $16 \mathrm{~dB}$ when the stimulation was by BC. Statistically different threshold shifts between the two types of lesions were found where the $\mathrm{AC}$ threshold shifts for a glued stapes at 2 and $4 \mathrm{kHz}$ were 9 to $18 \mathrm{~dB}$ greater than for a severed ossicular chain, and the $\mathrm{BC}$ threshold shifts for a glued stapes at 4 and $12 \mathrm{kHz}$ were 8 to $9 \mathrm{~dB}$ greater than for a severed ossicular chain.
\end{abstract}

Keywords: guinea pig; bone conduction; threshold; compound action potential; middle ear lesion 


\section{Introduction}

There are two main pathways for human hearing. In the first pathway, sound conducted through the air (air conduction, AC) enters the ear canal and impacts the eardrum, which transmits the sound through the ossicular chain in the middle ear, and reach the cochlea inducing a sound pressure in the inner ear fluid resulting in a traveling wave on the basilar membrane and finally cause a hearing perception. In the second pathway, sound vibration conducted by the skull bone (bone conduction, BC) is transmitted to the inner ear resulting in a motion of the bone encapsulating the inner ear and thereby inducing a sound pressure inside the inner ear fluid resulting in a hearing perception (Stenfelt and Goode 2005, Stenfelt 2011). Bone conduction hearing is important for differentiating between sensorineural and conductive hearing loss as well as providing hearing when normal AC hearing aids are contraindicated (Snik, Mylanus et al. 2002).

Animal models are common and important in hearing research, where often smaller animals such as guinea pigs, rats and mice are used (Fridberger, Widengren et al. 2004, Reis, Dalmolin et al. 2017). One such animal is the guinea pig that is easy to handle. The auditory anatomy of the guinea pig differs from the human as the guinea pig's cochlea protrudes into the bulla and has three and half cochlear turns compared to the human two and a half turns, and the incus and malleus are fused in the guinea pig while the same joint is mobile in the human (Albuquerque, Rossato et al. 2009). Another major difference is that a large part of the cochlea in the guinea pig is encapsulated by thin bone while it is imbedded in thick skull bone in the human. Moreover, important for BC sound, the skull bone is in general much thinner in the guinea pig than in the human which can influence the wave propagation in the bone. However, the low-frequency hearing range of the guinea pig is similar to the human ear. Although slightly different from the human, guinea pigs' ears are a common model for hearing experiments.

The estimation of hearing thresholds can be done with objective or subjective methods in humans while objective or behavioural methods are used in animals. A threshold of hearing defines the lowest stimulation level required to detect sound and is used to describe hearing sensitivity and the lower end of the dynamic range of hearing. This is commonly achieved in the human by lowering the stimulation level until the person no longer respond to the stimulation and the faintest level the person can detect is defined as the threshold. The same methodology can be used in objective tests, such as brainstem response audiometry, where the lowest level that can elicit a clearly visible neural response is defined as the hearing threshold. A similar method based on auditory evoked potentials is often used to estimate the hearing thresholds in animals, for example measurements of auditory brainstem responses (ABRs) or compound action potentials (CAP) in the cochlea. The CAP represents the summed response of the auditory nerve fibres and can be recorded by an electrode placed at the round window. Since the threshold is defined as the lowest stimulation level that can elicit a stable auditory evoked response, the threshold depends on the noise level, for example the integration time or number of averages for each stimulation level. Other factors may also influence the hearing threshold, for the guinea pig the hearing thresholds are affected by age (Dum, Schmidt et al. 1980, Ingham, Thornton et al. 1998), pigmentation (albino or pigmented) (Crifo 1973), and prolonged noise exposure (Suits, Brummett et al. 1993). Older age, albinism, and longer time exposure to noise affected the guinea pigs' auditory thresholds negatively.

Few studies investigated the $\mathrm{BC}$ hearing in guinea pigs. One general problem with $\mathrm{BC}$ hearing thresholds in guinea pigs is the reference entity used. In hearing by AC, the sound pressure level, either in the sound field or close to the eardrum in the ear canal, is used as the reference. However, for BC stimulation, no similar reference has been used. This is unfortunate since it prevents easy comparison between studies. In humans, the $\mathrm{BC}$ hearing reference is the dynamic force provided by a $175 \mathrm{~mm}^{2}$ circular plate pressed onto the skin at the mastoid with a static force of 5.4 Newtons. A similar approach could be used for guinea pigs, or any other species, but require ways to calibrate the dynamic stimulation force. A drawback with such a system is that it most probably needs specific calibrations for different strains and sizes of the animals. Another way to reference the stimulation is to measure the resulting motion in the 
bone. Here, we suggest measuring close to the animal's cochlea to provide stable data. This circumvent problems with different stimulation transducers as well as different placements of the $\mathrm{BC}$ transducer.

Besides facilitating comparison between studies, a reference for $\mathrm{BC}$ hearing in the guinea pig also enables detection of middle ear lesions. The use of $\mathrm{AC}$ and $\mathrm{BC}$ hearing thresholds can reveal a conductive component of the hearing loss that is not possible with $\mathrm{AC}$ hearing thresholds alone. In humans, it is often assumed that the middle ear lesion does not affect the $\mathrm{BC}$ thresholds and the difference between $\mathrm{AC}$ and $\mathrm{BC}$ thresholds is a measure of the conductive component. In reality, lesions commonly affect the $\mathrm{BC}$ thresholds, but the effect of a middle ear lesion is less for $\mathrm{BC}$ hearing than it is for AC hearing (Stenfelt 2013). In the guinea pig, it is not known how much a middle ear lesion affects the $\mathrm{BC}$ sensitivity. Consequently, to estimate the size of the conductive component in a guinea pig based on $\mathrm{AC}$ and $\mathrm{BC}$ hearing thresholds, the effect of the lesion itself on the $\mathrm{BC}$ hearing thresholds must be known.

The current study aims to provide reference data for $\mathrm{BC}$ hearing in the guinea pig. The $\mathrm{BC}$ thresholds will be related to the guinea pig cochlear vibration to facilitate comparison of $\mathrm{BC}$ thresholds. Moreover, the CAP caused by AC and BC will be compared in terms of growth functions and the effect on $\mathrm{AC}$ and $\mathrm{BC}$ hearing thresholds caused by middle ear lesion of either ossicular discontinuity or total fixation of the stapes (simulating effects of otosclerosis) will be evaluated.

\section{Material and Methods}

This study was approved by the research animal ethical review board: 19-14. And all experiments followed EU Directive 2010/63/EU for animal experiments.

\section{Guinea Pigs}

Twenty-four albino Dunkin-Hartley female Guinea pigs (6-10 weeks old) were included in the experiments and they had a mean weight of $478 \mathrm{~g}$. They were randomly divided into one of two groups where group $1(\mathrm{n}=10)$ had the ossicular chain cut as a conductive impairment and group $2(\mathrm{n}=14)$ had the stapes glued to the surrounding bone simulating an osteosclerotic ear. Two of the Guinea pigs in the stapes-glued group died during the middle ear manipulation surgery, and they are only included in the baseline data ( $\mathrm{AC}$ and $\mathrm{BC}$ thresholds for Guinea pigs). Consequently, the stapes-glued group contained 12 Guinea pigs.

After weighting the animal, it was anaesthetized with an intraperitoneal injection of $10 \mathrm{mg} / \mathrm{kg}$ Xylazine and $40 \mathrm{mg} / \mathrm{kg}$ Ketamine. The dosage of Xylazine was reduced to half of the initial dose during surgical preparation and the dosage of Ketamine was kept constant, when additional injections were required to maintain deep anaesthesia after $40 \mathrm{~min}$. In addition, eye drops, Oculentum simplex APL, were administered to prevent the eyes from drying during surgery, and a long-acting local anaesthetic (bupivacaine, $0.2 \mathrm{mg} / \mathrm{kg}$ ) was applied around the animal's ear canal.

Before starting the experiment, the presence of the Preyer's reflex was verified in each animal, and the external auditory canal was examined to exclude animals with infections. Following anaesthesia, the fur around the ear canal was shaved, bupivacaine injected, and the guinea pig placed on a heating pad $\left(\sim 37^{\circ} \mathrm{C}\right)$. An incision from the top of the head to the back of the ear was made and the soft tissue above the bone removed. An opening into the bulla of approximately $8 \mathrm{~mm}$ was made exposing the round window (RW) and middle ear structures. A silver wire electrode was placed on the RW while two other needle electrodes were placed through the skin on the left cheek and homolateral back leg. Positioning of the RW electrode and all middle ear manipulations were done under an operating microscope (Zeiss $16549(\mathrm{f}=160))$. 
The vibration transducer was applied to the guinea pig head using a specially made threaded adaptor which was attached with dental cement (3M ESPE Durelon carboxylate cement) to the vertex of the guinea pig. This adaptor was a $6 \times 6 \times 10 \mathrm{~mm}$ brass cuboid with threaded holes going through the centre of each side. Once positioned on the guinea pig's head, the adaptor facilities rigid attachment of the BC transducer that was applied at the top of the adaptor facing down.

\section{Measurement set-up}

The signals were generated and recorded in a computer connected to a National instruments USB-4431 board, with 4 input and 1 output channels. The round window electrode was connected to an amplifier (NPI, EXT-02F-1) at a gain of 10,000 and sampled by the USB-4431 board using custom software. The acoustic stimulus was generated by the USB-4431 board connected to a power amplifier (SA1 Stereo amplifier powered via the System 3 zBus) and then to a speaker (ND13TE, Parts Express) for acoustic stimulation. When the stimulation was provided as BC sound, the output from the USB-4431 was routed directly to a BC transducer from a BAHA Classic 300 (Cochlear Inc.) hearing aid where the casing and electronics were removed (size approximately $15 \times 15 \times 5 \mathrm{~mm}$, weight approximately 20 grams). The vibrations of the guinea pig skull bone and cochlear promontory were measured in three orthogonal directions with a 3D Laser Doppler Vibrometer (LDV, Polytech), equipped with a CLV-3D sensor head and CLV-3000 controller.

The electrophysiological measurements were performed in an acoustically and electrically shielded chamber. The stimulus generation and recording were done in LabView using a specially written software.

\section{Measurement procedure}

For the AC measurements, the guinea pig was placed in the acoustically and electrically shielded chamber, and a small tube from the speaker was inserted into the guinea pig's ear canal. The output of the speaker was calibrated to provide AC stimulation in sound pressure level (SPL) in the guinea pig's ear canal. The stimulation was a $6 \mathrm{~ms}$ long tone burst with $1 \mathrm{~ms}$ sine gated rise and fall and a $2 \mathrm{~ms}$ silence resulting in $10 \mathrm{~ms}$ interstimulus intervals. The stimulation was presented with alternating polarities and, in total, 400 stimuli were used for each level and frequency resulting in 4 seconds for each estimate. The measurements started with a level of $90 \mathrm{~dB}$ SPL at $2 \mathrm{kHz}$ and continued at increasing frequencies according to the test frequencies used $(2,4,8,12,16$, and $20 \mathrm{kHz})$. After each measurement run of 6 frequencies at a level, the level was decreased by $10 \mathrm{~dB}$ and a new measurement run starting at $2 \mathrm{kHz}$ was initiated until the stimulus level was down to $30 \mathrm{~dB}$ SPL. The response measure for each frequency and level was the compound action potential (CAP) obtained by the electrode at the RW. It was estimated by averaging the 400 responses for each stimulation frequency and level.

For the $\mathrm{BC}$ measurements, the vibrator was attached to the top of the adaptor. The hearing thresholds with $\mathrm{BC}$ stimulation in the guinea pig is unknown and the stimulation levels were chosen to include levels above and below the $\mathrm{BC}$ threshold according to preliminary experiments performed prior to the data collection. Identical stimuli (voltage to the transducers) were used for $\mathrm{BC}$ and $\mathrm{AC}$ measurements and the estimation of the CAP was done similarly for the two stimulation modalities. The guinea pig with the $\mathrm{AC}$ and $\mathrm{BC}$ stimulation and the measurement directions are illustrated in Fig 1. The orientation of the coordinate system shown in Fig 1 is $\mathrm{x}$-direction: ventral, y-direction: posterior, and z-direction: left.

After the $\mathrm{AC}$ and $\mathrm{BC}$ thresholds were obtained, in the animals belonging to group 1 the ossicular chain was cut between malleus and incus (I-M joint) by a sharp hypodermic needle under microscope and visual inspection verified the separation between the two ossicles. If the animal belonged to group 2 the stapes was glued to the surrounding bone by histoacryl glue (B.Brown). After the glue settled, the 
fixation of the stapes was verified with a pick. The $\mathrm{AC}$ and $\mathrm{BC}$ threshold estimation was repeated in the new condition. As stated above, two of the guinea pigs in the stapes glued group died subsequent to the manipulation and were excluded from the analysis of the effect from a middle ear lesion.

The animal was euthanized by an injection of $1 \mathrm{ml}$ pentobarbital sodium $(60 \mathrm{mg} / \mathrm{ml})$ in the abdomen after finalizing all CAP measurements. Subsequent to euthanasia, the guinea pig was positioned so the three laser beams could access a position on the cochlear bone between the RW and the oval window. The animal was aligned with the orientation of the coordinate system of the 3D-LDV system. The BC vibrator was excited by a 2 second chirp signal from $1 \mathrm{kHz}$ to $50 \mathrm{kHz}$ with 20 repetitions and the vibration of the cochlear bone obtained in three dimensions using the 3D-LDV system. Although the vibration measurements were obtained after termination of the guinea pig, all vibration measurements were finalized within 30 minutes after death and the mechanical properties important for vibration transmission of the animal are assumed equal to a living animal. During the vibration measurement, it was ensured that the reflection of the three laser beams was high indicated by $100 \%$ laser response on the controller. The vibration in the 3 directions was obtained by recording the laser signals through the $\mathrm{I} / \mathrm{O}$ card and analyzing the sampled data in Matlab. The whole measurement usually took around 12 hours for each animal.

\section{Analysis}

The analysis was conducted in Matlab. The use of alternating polarity reduced contributions from the cochlear microphonic potentials, enabling easier identification of the CAP voltage. The CAP was manually identified in the averaged responses (Fig 2a). Only CAPs that was clearly identifiable were included and the magnitudes of the CAP wave P1 were identified and stored for further analysis. For each frequency, the CAP voltages were linearly fitted in relation to the stimulation level in $\mathrm{dB}$ scale using the Matlab function polyfit (Fig 2b). This gave a linear slope and the stimulation level that resulted in zero voltage CAP according to the fitted slope was defined as the threshold level. The same method was done for BC stimulation to obtain the guinea pig BC thresholds (Fig 3). In Fig. 3a, the CAP was not identifiable at the 3 lowest stimulation levels. So, only the four CAP value for the highest stimulation levels were included in the fitting process to achieve the $\mathrm{BC}$ threshold and slope (Fig. 3b). The same process was used to analyse all $\mathrm{AC}$ and $\mathrm{BC}$ data.

\section{Results}

\section{AC thresholds}

The average AC thresholds for the 24 guinea pigs were $25.1 \pm 2.2,22.7 \pm 3.1,12.9 \pm 2.2,16.4 \pm 1.7$, $17.6 \pm 3.2,6.4 \pm 3.9 \mathrm{~dB}$ SPL (mean $\pm \mathrm{SEM}$ ) at the frequencies 2 to $20 \mathrm{kHz}$, also shown in Fig $4 \mathrm{a}$ and Table 1. These thresholds are for a CAP voltage of 0 volts. There is a general trend of lower thresholds with frequency of approximately $20 \mathrm{~dB} /$ decade with slightly lower threshold at $8 \mathrm{kHz}$ and slightly higher thresholds at $16 \mathrm{kHz}$. Some previous studies report the guinea pig AC thresholds as the $10 \mu \mathrm{V}$ p-p CAP. As the CAP is obtained as the peak amplitude in the current study, a threshold of $5 \mu \mathrm{V}$ CAP here is approximately equal to a $10 \mu \mathrm{V}$ p-p CAP and is also calculated (Fig $4 \mathrm{~b}$, Table 1). Due to differences of the slopes computed at the frequencies, the threshold curves with a threshold definition of $5 \mu \mathrm{V} \mathrm{CAP}$ (Fig 4b) differ from the threshold definition of 0 V CAP (Fig 4a).

\section{BC thresholds}


In these experiments, the $\mathrm{BC}$ transducer was applied in the ventral direction (Fig 1) at the vertex of the guinea pig. The $\mathrm{BC}$ thresholds were obtained in a 2-stage process. First, the relationship between the voltage to the $\mathrm{BC}$ transducer and the vibration velocity of the cochlear promontory was obtained by the use of the 3D Laser Doppler Vibrometer to measure the cochlear vibration for a given stimulation voltage. Figure 5a shows the average absolute velocity in three orthogonal directions of the guinea pig cochlear promontory when 1 volt is applied to the $\mathrm{BC}$ transducer. As expected, the vibrational response in the posterior direction has the highest amplitude. Also, the velocity decreases with frequency which is caused by the transducer design. Figure $5 \mathrm{~b}$ shows the relative contribution of each vibration direction when the total vibration $(0 \mathrm{~dB})$ is the square root of the squared sum of all directions; it indicates that the posterior direction is 3 to $5 \mathrm{~dB}$ greater than the ventral direction. The left direction relative component falls with frequency and is nearly $25 \mathrm{~dB}$ below the posterior direction component at $20 \mathrm{kHz}$. Consequently, the current $\mathrm{BC}$ thresholds are primarily due to stimulation in the posterior direction. For the estimations of the $\mathrm{BC}$ thresholds, the square-root of the sum of the squared velocities $\left(V_{T O T}\right)$ in the three orthogonal directions was used.

$V_{T O T}=\sqrt{V_{X}^{2}+V_{Y}^{2}+V_{Z}^{2}}$

With the result from Fig 5 , the $\mathrm{BC}$ thresholds in relation to the velocity of the cochlear promontory bone are presented in Fig 6 . When the thresholds are defined as CAP equal to 0 volt, the $\mathrm{BC}$ thresholds were for the 24 guinea pigs on average $1.71 \pm 2.45,-0.09 \pm 1.85,-4.34 \pm 1.41,-9.93 \pm 1.27,-4.74 \pm 1.67,2.90$ $\pm 2.12 \mathrm{~dB}$ re $1 \mu \mathrm{m} / \mathrm{s}$ (mean \pm SEM) for the frequencies 2 to $20 \mathrm{kHz}$ (Fig 6a, Table 1). The thresholds fall with frequency from $1.71 \mathrm{~dB}$ re $1 \mu \mathrm{m} / \mathrm{s}$ at $2 \mathrm{kHz}$ to $-9.93 \mathrm{~dB}$ re $1 \mu \mathrm{m} / \mathrm{s}$ at $12 \mathrm{kHz}$, approximately equal to a reduction of $12 \mathrm{~dB}$. At the higher frequencies, 16 and $20 \mathrm{kHz}$, the $\mathrm{BC}$ thresholds increase with frequency to $2.90 \mathrm{~dB}$ re $1 \mu \mathrm{m} / \mathrm{s}$, forming a v-shaped threshold curve. This change in slopes with frequency suggest that the mechanisms causing $\mathrm{BC}$ hearing in the guinea pig differ between the lower frequencies (2 to $12 \mathrm{kHz}$ ) and the higher frequencies (12 to $20 \mathrm{kHz})$. Similar to the AC thresholds, the $\mathrm{BC}$ thresholds at a CAP of $5 \mu \mathrm{V}$ were computed and are shown in Fig 6b (Table 1). Different from the $\mathrm{AC}$ thresholds, the $\mathrm{BC}$ threshold curves have a similar morphology at both a CAP of $0 \mu \mathrm{V}$ (Fig 6a) and of $5 \mu \mathrm{V}$ (Fig 6b).

\section{$A C$ and $B C$ CAP growth function}

The CAP growth function is estimated by computing the linear slope of the input stimulation (in $\mathrm{dB}$ ) and output CAP (in volts) using the regression analysis shown in Fig $2 \mathrm{~b}$. Their values for $\mathrm{AC}$ in the frequency range $2-20 \mathrm{kHz}$ are $0.18 \pm 0.02,0.41 \pm 0.04,0.54 \pm 0.04,0.58 \pm 0.05,0.70 \pm 0.07,0.27 \pm$ 0.04 and for $\mathrm{BC}$ in the same frequency range $0.21 \pm 0.03,0.39 \pm 0.04,0.38 \pm 0.03,0.45 \pm 0.04,0.29 \pm$ $0.02,0.24 \pm 0.02 \mu \mathrm{V} / \mathrm{dB}$ (mean $\pm \mathrm{SEM}$ ) (Fig 7, Table 1). The relation between stimulation level and

CAP voltage was in most cases well approximated with a straight line and the $r^{2}$ was around 0.95 for both $\mathrm{AC}$ and $\mathrm{BC}$ stimulation. The growth function $(\mu \mathrm{V} / \mathrm{dB})$ for the CAP in Fig 7 show similarities but also differences between $\mathrm{AC}$ and $\mathrm{BC}$ stimulation. To investigate these differences of CAP growth function further, a repeated measures ANOVA with stimulation modality (AC and $\mathrm{BC})$ and stimulation frequency as factors showed significant effect of modality $[\mathrm{F}(1,23)=26.84, \mathrm{p}<0.001]$, frequency $[\mathrm{F}$ $(5,115)=35.46, p<0.001]$ and the interaction of modality and frequency $[F(5,115)=17.02, p<0.001]$. An analysis of the CAP growth function $95 \%$ confidence intervals revealed only a significant difference between the $\mathrm{AC}$ and $\mathrm{BC}$ growth functions at $16 \mathrm{kHz}$, for all other frequencies the $95 \%$ confidence intervals for the $\mathrm{AC}$ and $\mathrm{BC}$ growth functions overlapped.

\section{Effect of middle ear lesion}

The threshold shifts after manipulating the middle ear are shown in Fig $8 \mathrm{a}$ for $\mathrm{AC}$ and Fig $8 \mathrm{~b}$ for $\mathrm{BC}$ stimulation. In Fig 8, dashed line indicates severing the IM joint and solid line indicates that the ossicles were glued to the surrounding bone. Except for the two lowest frequencies for severing the ossicles and 
the lowest for gluing the ossicles, the mean of $\mathrm{AC}$ threshold shifts fall between 36 and $53 \mathrm{~dB}$. The mean of $\mathrm{BC}$ threshold shifts was all from 3 to $16 \mathrm{~dB}$. No general trends were seen in the data presented in Fig 8.

To investigate the threshold shifts further, a repeated measures ANOVA were conducted with stimulation modality (AC and $\mathrm{BC}$ ) and frequency as within-subject factors and manipulation (severing or gluing) as between-subject factors. According to the ANOVA there were main effects of stimulation modality $[\mathrm{F}(1,20)=434.56, \mathrm{p}<0.001]$, frequency $[\mathrm{F}(5,100)=576.85, \mathrm{p}<0.001]$ and manipulation $[\mathrm{F}$ $(1,20)=4.40, p=0.049]$. The interaction between stimulation modality and manipulation type was not significant but the interaction between frequency and manipulation type was significant $[\mathrm{F}(5,100)=$ $586.24, \mathrm{p}<0.001]$ as well as between stimulation modality and frequency $[\mathrm{F}(5,100)=739.96, \mathrm{p}<$ 0.001]. The interaction between all three factors, stimulation modality, frequency and type of manipulation, was not significant.

When the $95 \%$ confidence interval for the measures were analysed, there were no overlap between the $\mathrm{AC}$ threshold shifts and $\mathrm{BC}$ threshold shifts at each frequency independent of manipulation type. Consequently, the threshold shifts at each frequency tested differ significantly between AC and BC stimulation. When the $95 \%$ confidence intervals were analysed between the type of manipulation for the same stimulation modality and frequency, there were significant differences for AC stimulation at $2 \mathrm{kHz}$ and $4 \mathrm{kHz}$ and for $\mathrm{BC}$ stimulation at $4 \mathrm{kHz}$ and $12 \mathrm{kHz}$. With $\mathrm{AC}$ stimulation at $2 \mathrm{kHz}$, the mean threshold shift for the glued ossicles was $32.8 \mathrm{~dB}$ while it was $23.7 \mathrm{~dB}$ for the severed ossicles, and at 4 $\mathrm{kHz}$ the mean threshold shift was $44.5 \mathrm{~dB}$ for the glued ossicles and $26.0 \mathrm{~dB}$ for the severed ossicles. The significantly different threshold shifts with $\mathrm{BC}$ stimulation were at $4 \mathrm{kHz} 7.4 \mathrm{~dB}$ for the severed ossicles and $16.4 \mathrm{~dB}$ for the glued ossicles, and at $12 \mathrm{kHz}$ it was $3.0 \mathrm{~dB}$ for the severed ossicles and 10.5 $\mathrm{dB}$ for the glued ossicles. It should be noted that the separation (non-overlap) of the $95 \%$ confidence intervals were 1.9 and $6.8 \mathrm{~dB}$ for the $\mathrm{AC}$ threshold shifts and 0.4 and $0.1 \mathrm{~dB}$ for the $\mathrm{BC}$ threshold shifts.

\section{Discussion}

\section{AC thresholds}

AC thresholds in the guinea pig have been estimated in several previous studies. In one such experiment (Horner and Cazals 1990), the CAP thresholds were defined by visual inspection of the averaged CAP response, resulting in approximately $18,13,8,5 \mathrm{~dB}$ SPL at 2, 4, 8, $20 \mathrm{kHz}$ (Table 1). In another experiment (Leggett $\mathrm{K}$ June 2018), the audiogram with the worst (highest) thresholds was selected with AC thresholds of 40, 30, 25, 40, $40 \mathrm{~dB}$ SPL at the frequencies 4, 8, 12, 16, $20 \mathrm{kHz}$ (Table 1). In another study (Bergin, Bird et al. 2015), the AC thresholds were defined as the lowest intensity where the N1P1-N2 complex could be visually identified at levels above $2 \mu \mathrm{V}$, which gave CAP threshold at 8,16 , $32 \mathrm{kHz}$ of 35, 30, $40 \mathrm{~dB}$ SPL respectively (Table 1). In another study (Mori, Fujimura et al. 2004), a threshold was defined as the lowest stimulus intensity at which an averaged N1-P1 amplitude of $10 \mu \mathrm{V}$ could be detected and they reported the CAP thresholds to be 22, 22, $26 \mathrm{~dB}$ SPL at 2, 4, $8 \mathrm{kHz}$ (Table $1)$.

The frequencies reported in the above-mentioned studies are similar as the ones used in the current study where some focused more on the lower frequencies and some on the higher frequencies. Our choice of including frequencies between $2 \mathrm{kHz}$ and $20 \mathrm{kHz}$ was a compromise between frequencies where the CAP can reliably be detected and the frequency range of human hearing. One problem comparing our data with similar results in other studies is the definition of threshold. In the current study an estimation of a CAP of $0 \mathrm{~V}$ was defined as the threshold while others have used different values of the CAP as the thresholds, all above $0 \mathrm{~V}$. As a result, our thresholds should be lower than those reported in the studies of others. That was the case for the studies mentioned above except for the CAP thresholds reported by Horner et al. (1990) who reported down to $10 \mathrm{~dB}$ lower AC thresholds than in the current study. The 
use of visual inspection of the CAP response in the Horner et al. (1990) should result in worse thresholds than those in the current study which computed the stimulation level of 0 V CAP and we do not have a good explanation for the deviation. The other studies showed up to $35 \mathrm{~dB}$ higher threshold levels based on their definition of the threshold. This comparison of thresholds illustrates the problem of defining a hearing threshold for guinea pigs when there is no consensus of threshold definition. However, the results indicate that the threshold data reported here are reasonable based on its definition.

Since the slopes of the CAP growth function were estimated (Fig 2b), the AC thresholds can be recalculated to any CAP value. This was done in Fig $4 \mathrm{~b}$ (Table 1) where the sound pressure levels for a $\mathrm{CAP}$ of $5 \mu \mathrm{V}$ peak are presented. These thresholds are similar to thresholds defined as CAP $10 \mu \mathrm{V}$ peakto-peak (Mori, Fujimura et al. 2004) as only the positive peak of the CAP was obtained in the current study. The two threshold curves in Fig 4 have different morphology which is caused by the difference in CAP slopes for different frequencies. Consequently, the definition of threshold (e.g. CAP voltage) do not only affect the absolute stimulation level but also the stimulation level as a function of frequency.

\section{BC thresholds}

Comparing $\mathrm{BC}$ thresholds in guinea pigs is even more difficult than comparing $\mathrm{AC}$ thresholds. We did not find any study that reported $\mathrm{BC}$ hearing thresholds in the guinea pig using a comparable entity. Bergin, Bird et al. (2015) reported the $\mathrm{BC}$ threshold change at 8,16 , and $32 \mathrm{kHz}$ with middle ear manipulations. However, they converted the $\mathrm{BC}$ stimulation to equivalent ear canal sound pressure level (dB SPLeq) resulting in the same CAP with AC stimulation in a normal ear. Consequently, those data cannot be used to determine a general $\mathrm{BC}$ stimulation level at threshold. There are a few studies that have reported vestibular responses using electrophysiology methods with $\mathrm{BC}$ stimulation in the guinea pig (Curthoys, Vulovic et al. 2016). However, that is different from BC generated hearing as the cochlea is not the receptor. Curthoys et al (2016) report the average threshold to be approximately $0.02 \mathrm{~g}$ (rms of the sum of the linear accelerations of the three axes in $g$ units) at frequencies between $100 \mathrm{~Hz}$ and $750 \mathrm{~Hz}$; at higher frequencies they report few and unstable results. Converted to velocity that is used in the current study, the thresholds of Curthoys et al (2016) become $320 \mu \mathrm{m} / \mathrm{s}$ at $100 \mathrm{~Hz}$ and $41.7 \mu \mathrm{m} / \mathrm{s}$ at $750 \mathrm{~Hz}$. The $\mathrm{BC}$ thresholds in the current study indicate close to constant acceleration thresholds at frequencies below $12 \mathrm{kHz}$, as illustrated in Figure 6 where the velocity thresholds fall with close to 5 $\mathrm{dB}$ per octave. If the Curthoys et al. (2016) thresholds are extrapolated to $2 \mathrm{kHz}$, the predicted threshold from their study is approximately $24 \mathrm{~dB}$ re $1 \mu \mathrm{m} / \mathrm{s}$, which is between $1.7 \mathrm{~dB}$ re $1 \mu \mathrm{m} / \mathrm{s}$ for CAP equal to $0 \mathrm{~V}$ and $34 \mathrm{~dB}$ re $1 \mu \mathrm{m} / \mathrm{s}$ for $\mathrm{CAP}$ equal to $5 \mu \mathrm{V}$ (Table 1). Consequently, the low-frequency BC hearing thresholds in the current study are in the same range as the vestibular obtained thresholds in the study by Curthoys et al (2016).

At present, there are no threshold data for $\mathrm{BC}$ stimulation in the guinea pig that can be used as reference thresholds. The current dataset provides means to compare results of $\mathrm{BC}$ hearing in guinea pigs. First, the thresholds are related to vibration of the cochlear promontory and the results are independent of the placement of the transducer as well as the characteristics of the transducers. Second, the thresholds are based on a CAP of 0 volts, but the slopes of the growth functions are provided in Fig 7 and the BC thresholds can be converted to any CAP based threshold. The limitation of the current dataset is that the vibration is dominated at the posterior direction and another configuration of the vibration components may give different sensitivity.

With the current configuration, the $\mathrm{BC}$ thresholds in terms of vibration velocity decreases from a frequency of 2 to $12 \mathrm{kHz}$ and reach the lowest value, $-10 \mathrm{~dB}$ re $1 \mu \mathrm{m} / \mathrm{s}$, at $12 \mathrm{kHz}$. At frequencies above $12 \mathrm{kHz}$, the thresholds increase with frequency up to the highest frequency measured, $20 \mathrm{kHz}$. The behaviour at frequencies below $12 \mathrm{kHz}$ is similar to the human where the velocity of the cochlear promontory at BC thresholds fall with frequency up to at least $4 \mathrm{kHz}$ (Eeg-Olofsson, Stenfelt et al. 2013). The result at frequencies above $12 \mathrm{kHz}$ is also found in the human for BC stimulation at higher frequencies if the hearing thresholds is a function of a constant volume displacement over the basilar 
membrane (Stenfelt 2015, Stenfelt 2016). According to the modelling approach of BC generated fluid motion in the inner ear in Stenfelt $(2015 ; 2016)$, a constant displacement of the cochlear promontory result in a nearly constant volume displacement over the basilar membrane at higher frequencies for both fluid inertial effects, inner ear compression effects, and middle ear inertial effects.

\section{CAP growth function}

Most papers on hearing in the guinea pig only provide information about the hearing thresholds but a few also provide information about the CAP as a function of stimulation level. In the current study the CAP growth function was estimated by a linear regression of the CAP amplitudes and stimulation levels above the threshold. This is an approximation as the growth function is not completely linear for the CAP amplitude related to the stimulation in dBs (level). However, the $r^{2}$ was around 0.95 for most of the estimated growth functions indicating that the approximation of a straight line was good.

The absolute value of the CAP depends on how it is defined and the configuration of the electrodes. In the current study, the CAP was defined as the peak amplitude while it is defined as the difference between the positive and negative peaks in some studies. Consequently, a CAP peak-to-peak value is about twice as the CAP peak value used here. When the AC CAP growth function is compared to the AC CAP growth functions reported in Liu, Wang et al. (2012), the current growth functions is 2 to 4 times shallower at the frequencies 4,8 , and $16 \mathrm{kHz}$ that are common for both studies, even after the results are adjusted for the peak-to-peak values reported by Liu, Wang et al. (2012) (Table 1). The AC growth functions reported by Bergin, Bird et al. (2015) at 8 and $16 \mathrm{kHz}$ are closer to the ones in the current study (Table 1). They report growth functions that are on the average 1.2 and 1.6 times steeper than the growth functions at 8 and $16 \mathrm{kHz}$ in the current study. The differences found between studies are believed to relate to the specific positions of the electrodes and method of analysing the CAP.

The growth functions were hypothesised to be independent of stimulation modality. However, the analysis showed that there was a significant difference between the AC CAP growth function and BC CAP growth function at $16 \mathrm{kHz}$. Moreover, the average results presented in Fig. 7 indicates generally steeper growth functions for AC CAP than BC CAP at frequencies between 8 and $16 \mathrm{kHz}$. In the study of Bergin, Bird et al. (2015), the AC and BC CAP growth functions were similar for the three frequencies tested, 8,16 and $32 \mathrm{kHz}$. The dissimilarity in the current study is believed to result in the difference in stimulation levels above threshold for $\mathrm{AC}$ and $\mathrm{BC}$. According to the average thresholds for $\mathrm{AC}$ stimulation, the stimulation levels between $30 \mathrm{~dB}$ SPL and $90 \mathrm{~dB}$ SPL gave CAP amplitudes that could be used for the regression estimation of the growth function. This was different for the BC CAP data where several of the stimulation levels fell below the threshold level and the CAP growth function estimate with BC stimulation is based on stimulation levels closer to the threshold levels. According to previous studies, the growth function is not completely linear but increases slightly with level. Consequently, since the $\mathrm{BC}$ growth function is based on lower stimulation levels relative to the threshold, the growth function also become shallower than with AC stimulation. To verify this reasoning, the AC CAP growth function at $16 \mathrm{kHz}$ was recalculated based on the stimulation levels 30 to $50 \mathrm{~dB}$ SPL. That computation lowered the average CAP growth function to $0.45 \mu \mathrm{V} / \mathrm{dB}$ (original 0.70 $\mu \mathrm{V} / \mathrm{dB}$ ) and the difference to the BC CAP growth function is no longer significant.

\section{Conductive losses}

The results from the artificial middle ear manipulations (gluing the stapes or cutting the I-M joint) is shown in Fig 8. For AC, the effect of the manipulations is greatest (35-53 dB threshold elevation) at frequencies from $4 \mathrm{kHz}$ and above, while at $2 \mathrm{kHz}$, the effect of the manipulations is limited to a mean elevation of $24 \mathrm{~dB}$ and $32 \mathrm{~dB}$ (Fig 8a). In addition, at $4 \mathrm{kHz}$, the effect of severing the I-M joint only elevated the threshold $26 \mathrm{~dB}$ while gluing the ossicles elevated the threshold around $46 \mathrm{~dB}$. At all other frequencies, the elevated thresholds were similar for AC stimulation with gluing the ossicles or severing the I-M joint. 
With $\mathrm{BC}$ stimulation, the effect of the middle ear manipulations results in less than $16 \mathrm{~dB}$ threshold elevations for most frequencies and the difference in threshold shifts for the two types of manipulations were within $10 \mathrm{~dB}$. The greatest threshold shifts were found with gluing the ossicles at the two lowest frequencies $(2$ and $4 \mathrm{kHz})$ and severing the I-M joint at the highest frequency investigated $(20 \mathrm{kHz})$. The two types of manipulations do affect the mechanics of the hearing systems differently, and it is therefore not surprisingly that the effect on the thresholds differs. Gluing the ossicles increases the impedance at the oval window leading to less fluid displaced at the oval window for BC stimulation while severing the I-M joint decreases the impedance at the oval window leading to more fluid displaced at the oval window (Stenfelt, Hato et al. 2002, Stenfelt, Hato et al. 2004). However, how these changes actually alter the $\mathrm{BC}$ thresholds are not clear but a lower impedance at the oval window seem to improve the $\mathrm{BC}$ sensitivity at low frequencies while an increased impedance at the oval window seem to decrease the BC sensitivity at mid frequencies (Stenfelt 2015). This is in line with the results in Figure 8b where the 2 and $4 \mathrm{kHz}$ threshold elevations are worse for gluing the ossicles than for severing the I-M joint. We do not have a good explanation for the difference of the threshold elevations seen at $20 \mathrm{kHz}$.

In the study by Bergin, Bird et al. (2015), the BC threshold elevations in guinea pigs was assessed subsequent to applying a rotating cutting burr to the incudomalleal complex. Although slightly different from the manipulations in our study, they report an average $\mathrm{BC}$ threshold elevation of $15 \mathrm{~dB}$ at $8 \mathrm{kHz}$ and $18 \mathrm{~dB}$ at $16 \mathrm{kHz}$. Unfortunately, they did not report the threshold elevation with AC stimulation. In a study on mice, Chen, Schwander et al. (2016) report 20 to $40 \mathrm{~dB}$ AC loss with fluid in the middle ear and 35 to $55 \mathrm{~dB}$ AC loss when the eardrum, malleus and incus was removed. The frequency range was 5.6 to $45.2 \mathrm{kHz}$. The loss with $\mathrm{BC}$ was limited by $10 \mathrm{~dB}$ for most frequencies for the two manipulations but had a maximum of $15 \mathrm{~dB}$ at the lowest frequency. Although slightly different frequency ranges, the levels of $\mathrm{AC}$ and $\mathrm{BC}$ loss with middle ear manipulations seem to be similar for mice as for guinea pigs.

One limitation of the current study is that no control animals were used but all animals reported were included in the manipulation of the ossicles. Consequently, part of the threshold elevations may be a result of decreased health status of the animal due to sedation and surgery. However, the overall health status of the animal was monitored during the entire time and any abnormal finding resulted in termination of the measurements. Consequently, there are no indications that the surgical procedure affected the data obtained in this study.

The result here facilitates normal $\mathrm{BC}$ thresholds for guinea pigs that can be used to detect a middle ear problem. The middle ear problem affects the $\mathrm{AC}$ thresholds more than the $\mathrm{BC}$ thresholds, and comparing the $\mathrm{AC}$ and $\mathrm{BC}$ threshold can provide information about the status of the middle ear. In a longer perspective, it would be desirable to have a system simpler than the requirement of vibration measurements at the cochlear promontory to assess the $\mathrm{BC}$ hearing thresholds. Such reference values could be obtained by a general-purpose $\mathrm{BC}$ transducer that could be attached to the vertex of the guinea pig or any other research animal. This should be the aim of future research for $\mathrm{BC}$ hearing in animals.

\section{Conclusion}

The way of estimating the hearing thresholds in guinea pigs by a regression of CAP voltage was robust and gave a high resolution of the threshold level. This study is the first to provide normal $\mathrm{BC}$ thresholds of the guinea pig in a reference entity that enables comparison between studies. The reference for BC stimulation was the cochlear bone vibration. The finding that the slopes of CAP growth function are slightly lower for $\mathrm{BC}$ than for $\mathrm{AC}$ stimulation at frequencies between 8 and $16 \mathrm{kHz}$ are believed to be a result of different dynamic ranges used for the regression computation and not an inherent difference in the response to $\mathrm{AC}$ and $\mathrm{BC}$ stimulation. A middle ear lesion causes a threshold shift typically of 40 to $50 \mathrm{~dB}$ for $\mathrm{AC}$ stimulation while it is at around $10 \mathrm{~dB}$ or lower when the stimulation is by $\mathrm{BC}$. The 
thresholds are similarly affected whether the middle ear manipulation is in the form of gluing the ossicles to the surrounding bone or disrupting the ossicles at the I-M joint.

\section{Acknowledgment}

This work was supported by Swedish Research Council.

\section{Tables}

Table 1

Summary of CAP thresholds and CAP growth functions in the current and other studies.

\begin{tabular}{|c|c|c|c|c|c|c|}
\hline \multirow[t]{2}{*}{ Study } & \multicolumn{6}{|c|}{ Frequency } \\
\hline & $2 \mathrm{kHz}$ & $4 \mathrm{kHz}$ & $8 \mathrm{kHz}$ & $12 \mathrm{kHz}$ & $16 \mathrm{kHz}$ & $20 \mathrm{kHz}$ \\
\hline \multicolumn{7}{|c|}{ AC thresholds (dB SPL) } \\
\hline Current, CAP $=0 \mathrm{~V}$ & 25.1 & 22.7 & 12.9 & 16.4 & 17.6 & 6.4 \\
\hline Current, CAP $=5 \mu \mathrm{V}_{\text {peak }}{ }^{*}$ & 59.7 & 36.9 & 23.4 & 26.5 & 27.5 & 31.9 \\
\hline Horner et al. 1990 & 18 & 13 & 8 & & & 5 \\
\hline Leggett 2018 & & 40 & 30 & 25 & 40 & 40 \\
\hline Bergin et al., 2015 & & & 35 & & 30 & \\
\hline Mori et al., 2004 & 22 & 22 & 26 & & & \\
\hline \multicolumn{7}{|c|}{$\mathrm{BC}$ thresholds (dB re $1 \mu \mathrm{m} / \mathrm{s}$ ) } \\
\hline Current, $\mathrm{CAP}=0 \mathrm{~V}$ & 1.7 & -0.1 & -4.3 & -9.9 & -4.7 & 2.9 \\
\hline Current, CAP $=5 \mu \mathrm{V}_{\text {peak }}{ }^{*}$ & 34.3 & 14.4 & 7.7 & 0.6 & 12.1 & 24.5 \\
\hline Curthoys et al. 2016 & 24 & & & & & \\
\hline \multicolumn{7}{|c|}{ CAP Growth function $(\mu \mathrm{V} / \mathrm{dB})$} \\
\hline AC, current & 0.18 & 0.41 & 0.54 & 0.58 & 0.70 & 0.27 \\
\hline $\mathrm{BC}$, current & 0.21 & 0.39 & 0.38 & 0.45 & 0.29 & 0.24 \\
\hline Liu et al. 2012 (AC) & & 3.6 & 4 & & 2.9 & \\
\hline $\begin{array}{l}\text { Bergin et al. } 2015 \text { (AC } \\
\text { and } B C \text { ) }\end{array}$ & & & 1.2 & & 1.6 & \\
\hline
\end{tabular}

*The CAP is the positive peak value which corresponds approximately to half of the peak-to-peak value 


\section{Figure legends}

Figure 1: The Guinea pig with the bone conduction transducer at the vertex and the tube for air conduction stimulation at the ear canal opening (right hand side). The coordinate system ( $x, y, z$ direction) used for the vibration measurement with the laser Doppler vibrometer is illustrated both from the front and the side of the animal.

Figure 2: a) A typical result of CAP voltage measurement at AC stimulation levels between 30 and 90 $\mathrm{dB}$ SPL. The peak voltage used for the analysis is indicated with a dot on the amplitude traces. b) An example of the regression calculation used to obtain the threshold levels. Here the stimulation frequency is $8 \mathrm{kHz}$.

Figure 3: a) A typical result of CAP voltage measurement at BC stimulation. The peak voltage used for the analysis is indicated with a dot on the amplitude traces. b) An example of the regression calculation used to obtain the threshold levels. Here the stimulation frequency is $8 \mathrm{kHz}$ and the stimulation levels are recalculated to voltage in $\mathrm{dB}$ re $1 \mathrm{mV}$.

Figure 4: a) The mean $\mathrm{AC}$ thresholds for the 24 guinea pigs computed as the $\mathrm{CAP}=0 \mathrm{~V}$ according to Fig 2. The vertical lines indicate $+/-1$ SEM. b) The mean AC thresholds for the 24 guinea pigs computed as the $\mathrm{CAP}=5 \mu \mathrm{V}$ according to Fig 2. The vertical lines indicate +/- 1 SEM.

Figure 5: a) The vibration of the guinea pig cochlea in the three orthogonal directions when the stimulation is 1 volt to the $\mathrm{BC}$ transducer. b) The relative contribution of each vibration direction when the square root of the squared sum of the three directions equal $0 \mathrm{~dB}$.

Figure 6: a) The mean $\mathrm{BC}$ thresholds as vibration velocity of the cochlear promontory for the 24 guinea pigs computed as the CAP $=0 \mathrm{~V}$ according to Fig 3 . The vertical lines indicate $+/-1$ SEM. b) The mean $\mathrm{BC}$ thresholds as vibration velocity of the cochlear promontory for the 24 guinea pigs computed as the $\mathrm{CAP}=5 \mu \mathrm{V}$ according to Fig 3 . The vertical lines indicate $+/-1$ SEM.

Figure 7: The CAP growth function for AC (solid line) and BC (dashed line) stimulation computed as the slope of the regression line in Figs 2 and 3. The vertical lines indicate $+/-1$ SEM.

Figure 8: a) Threshold shifts for AC stimulation when severing the ossicles or gluing the stapes to the bone. b) Threshold shifts for $\mathrm{BC}$ stimulation when severing the ossicles or gluing the stapes to the bone. The vertical lines indicate +/- 1 SEM. 
Figures
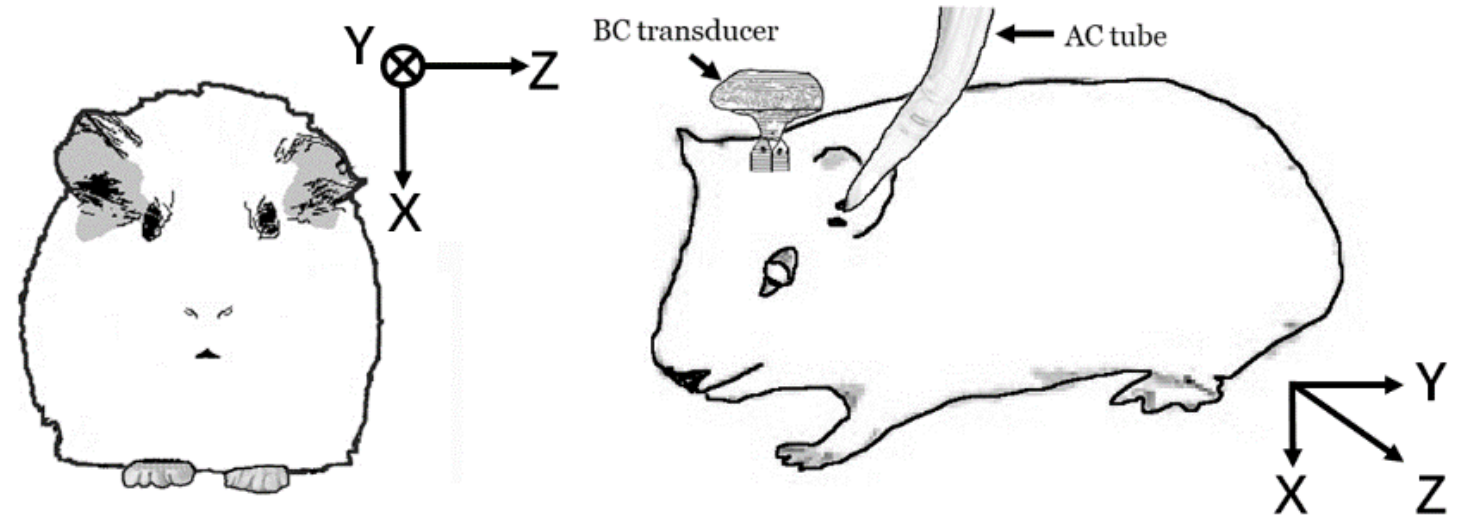

Figure 1 


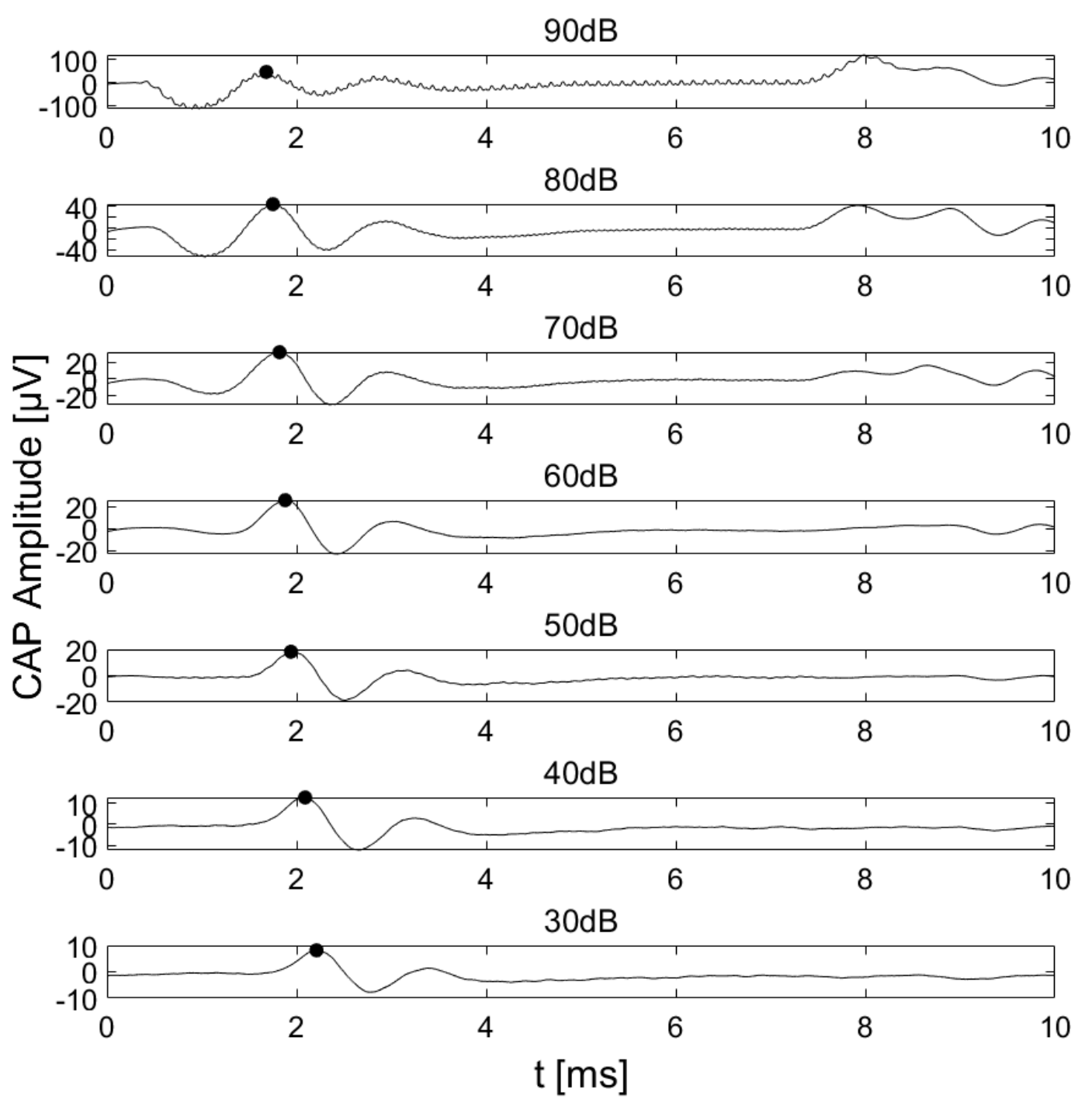

Figure 2a 


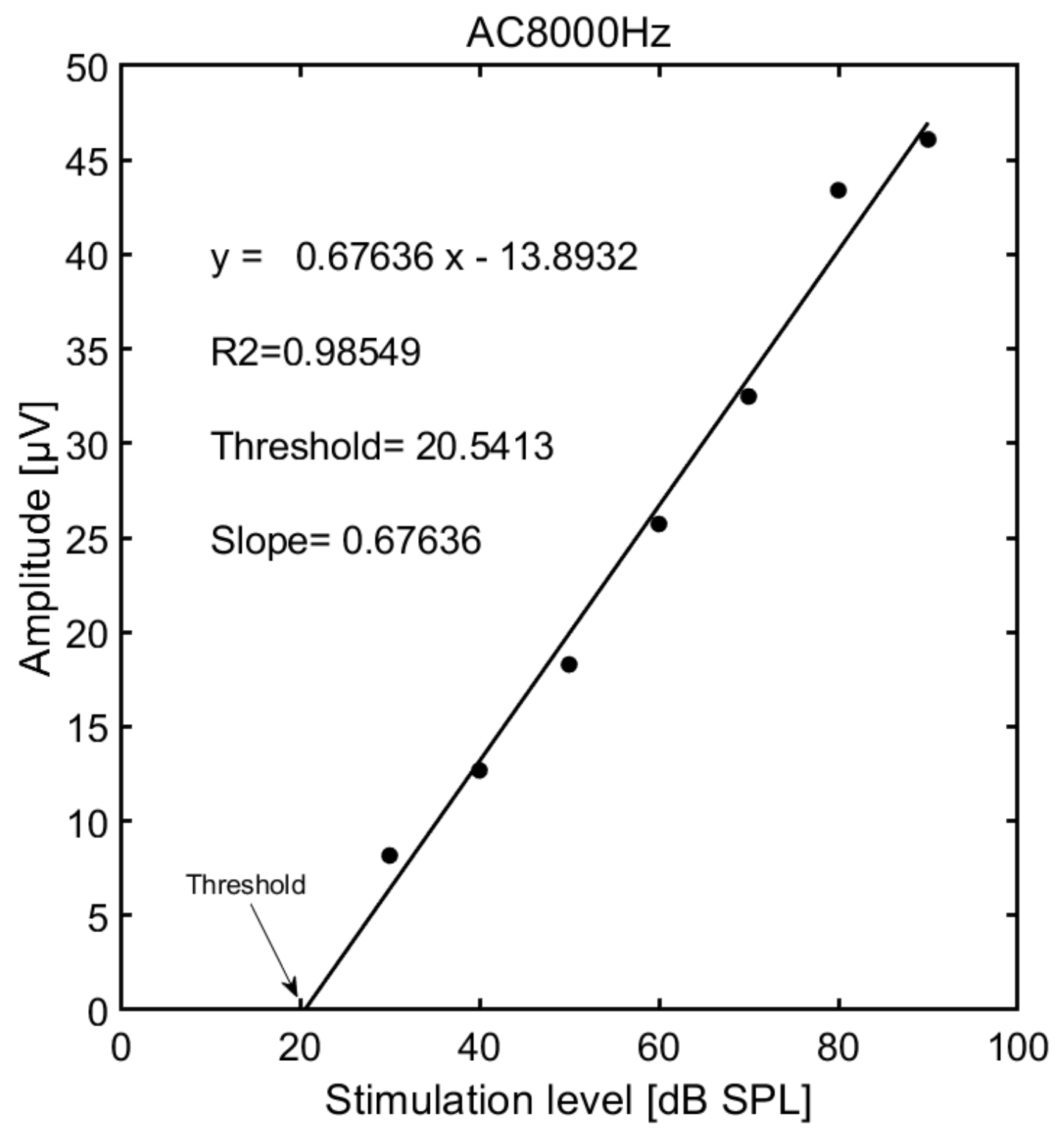

Figure $2 b$ 

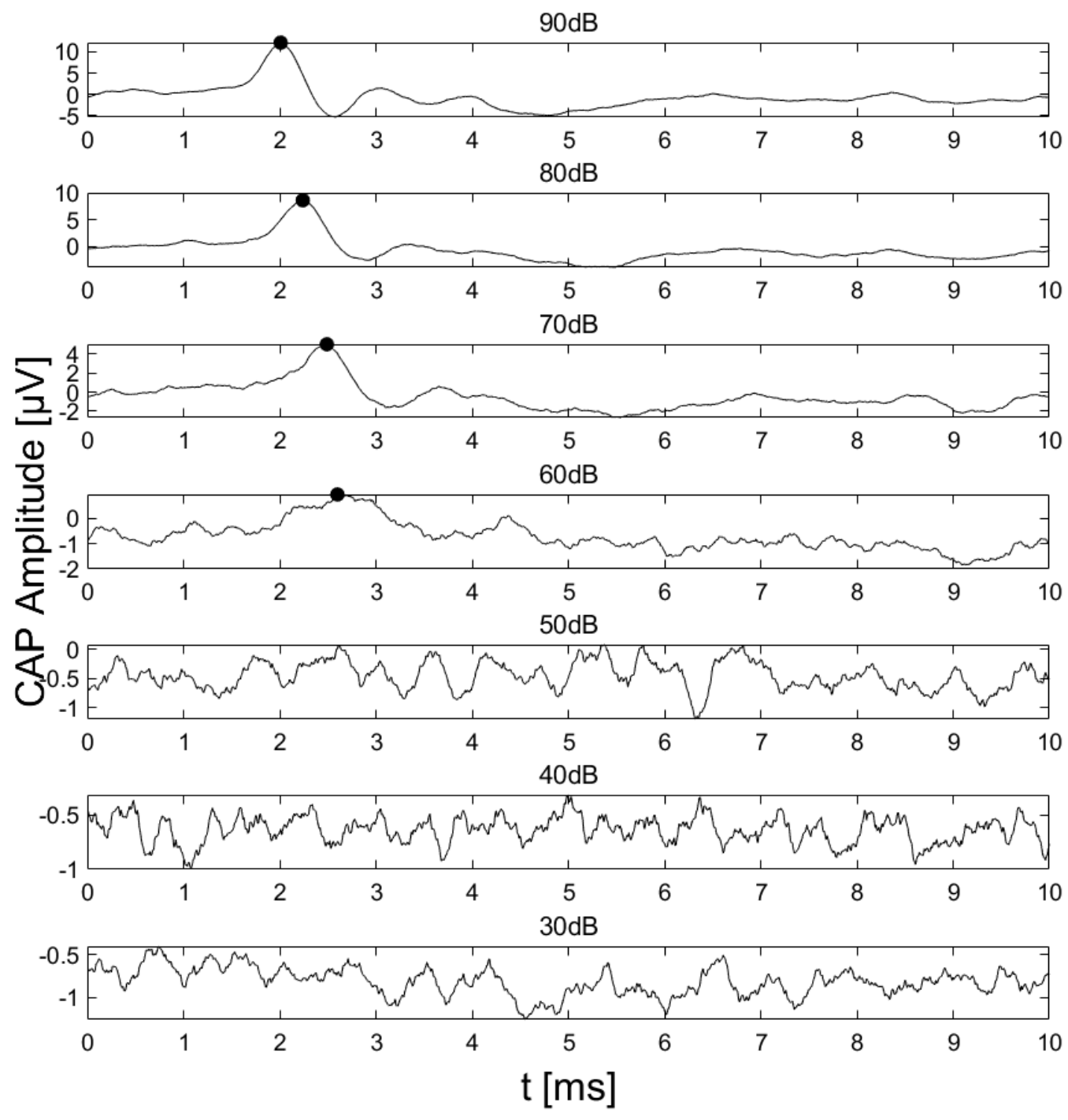

Figure 3a 


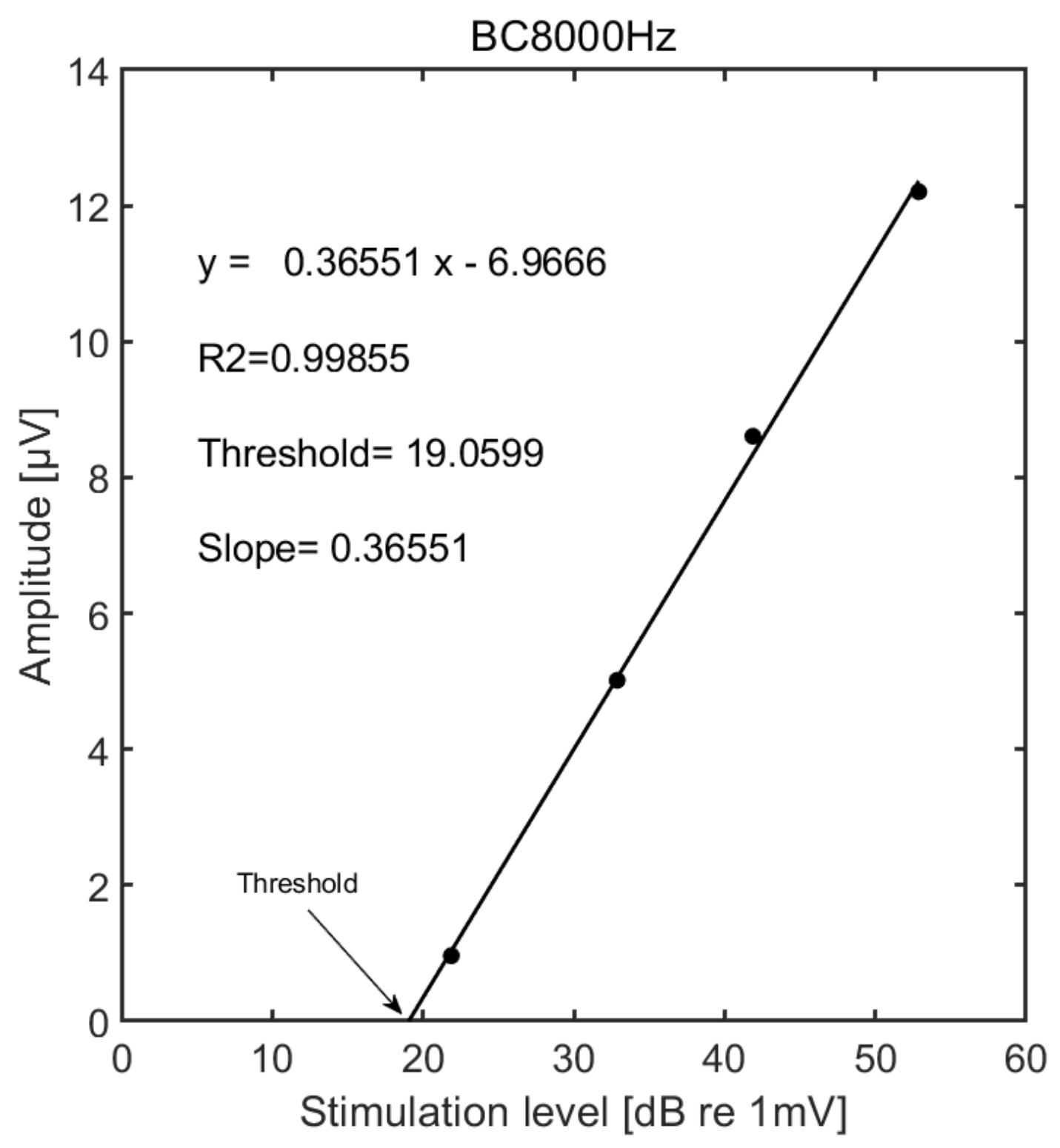

Figure $3 b$ 


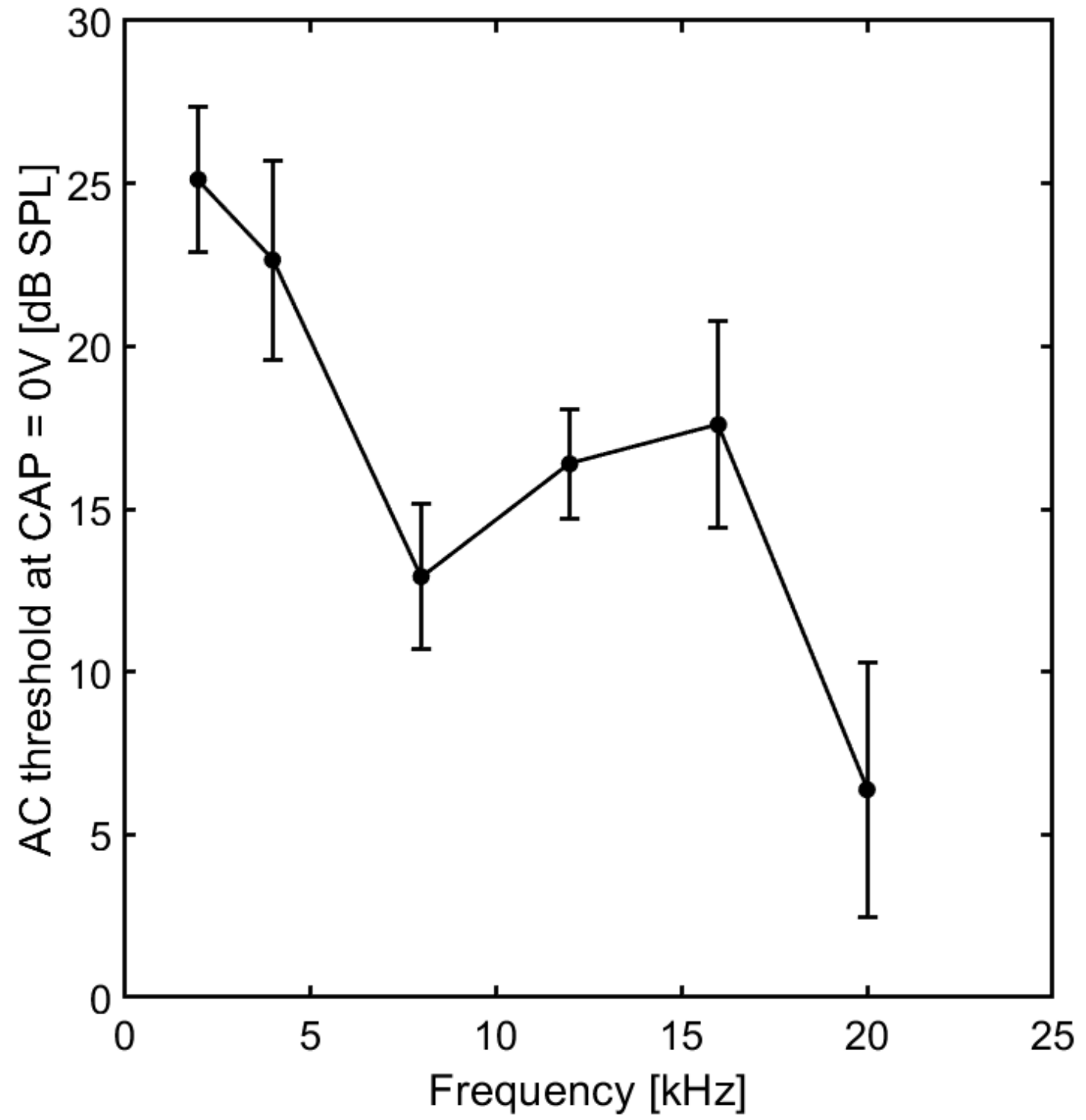

Figure 4a 


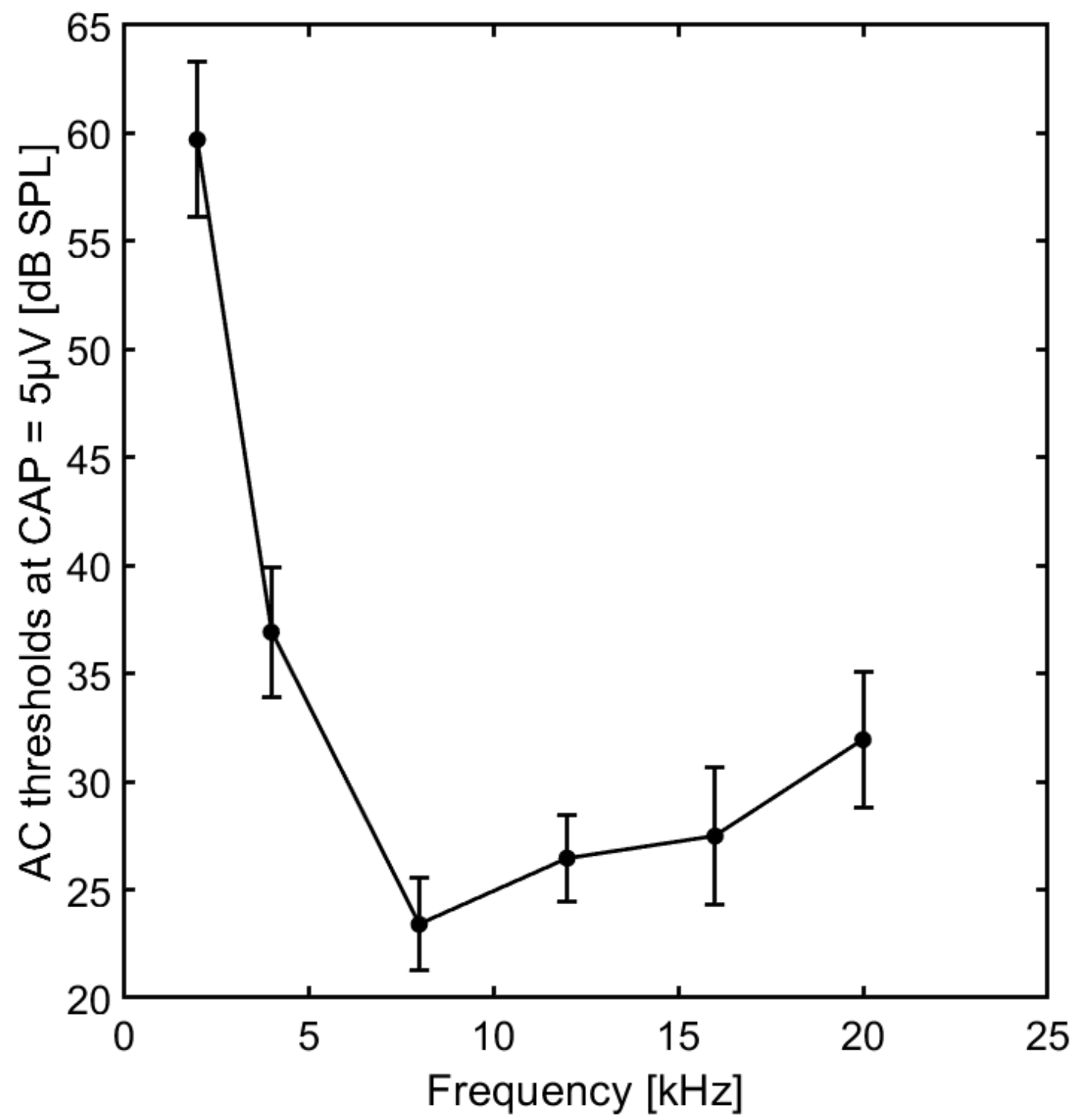

Figure $4 b$ 


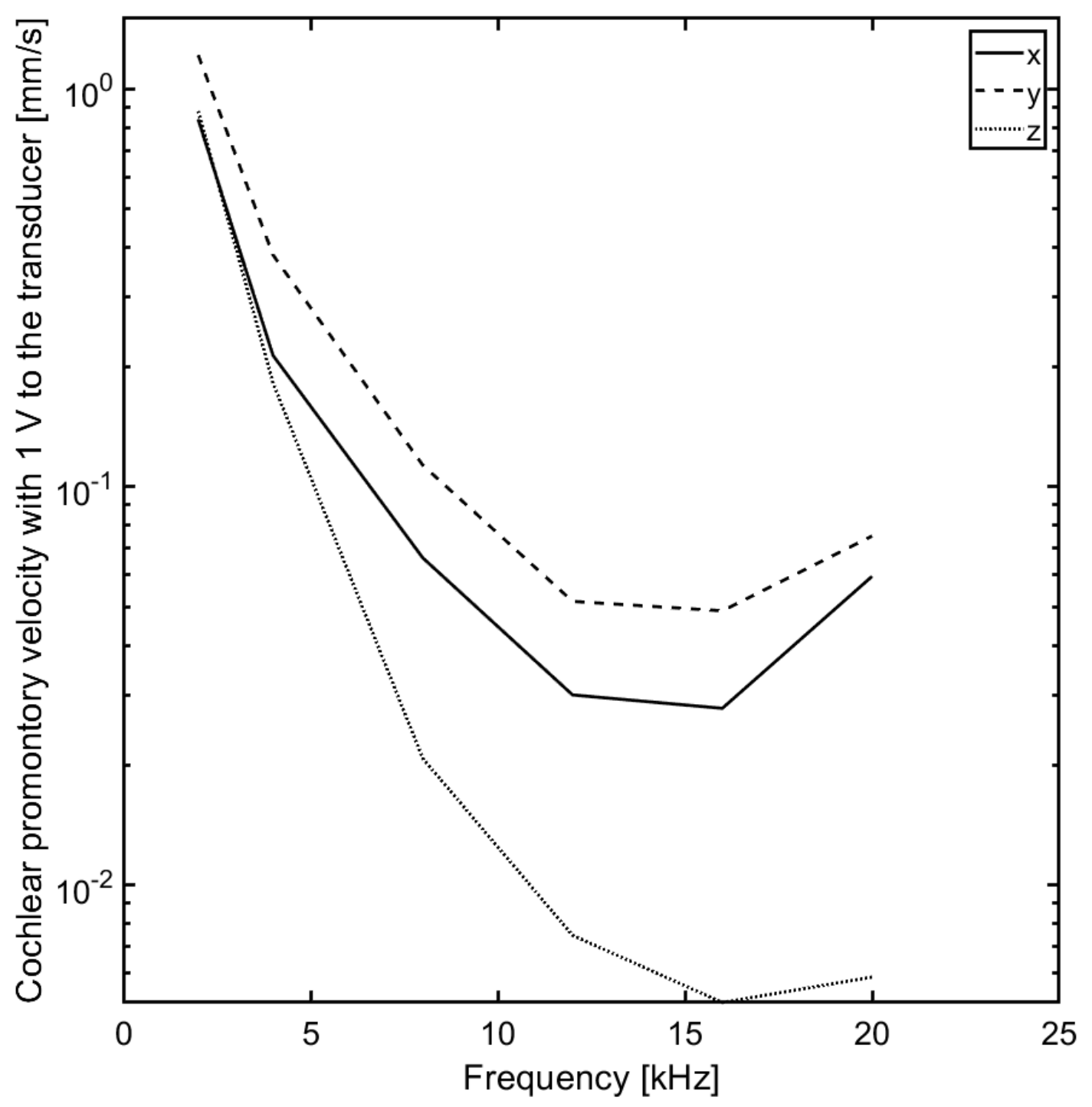

Figure 5a 


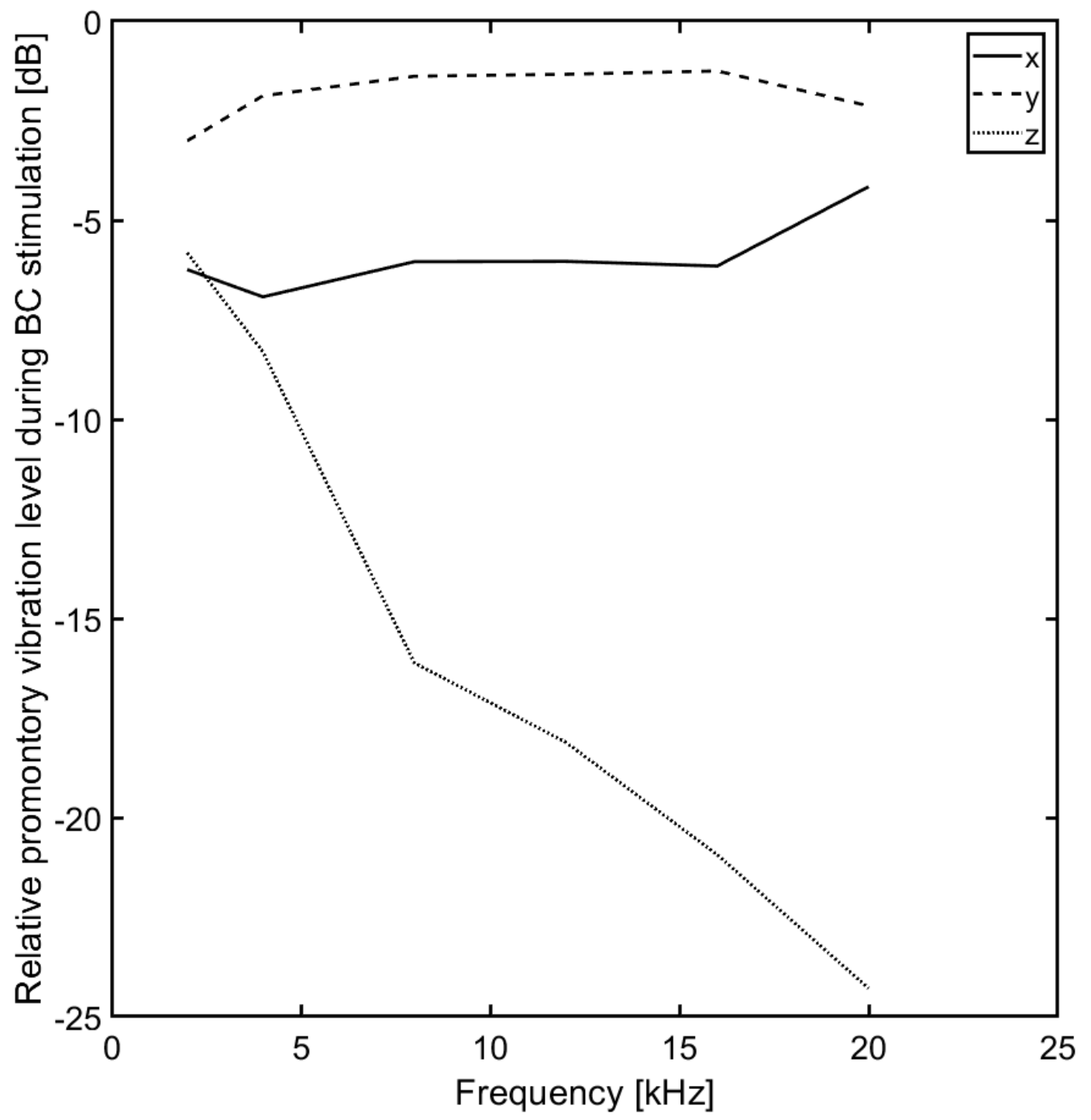

Figure $5 b$ 


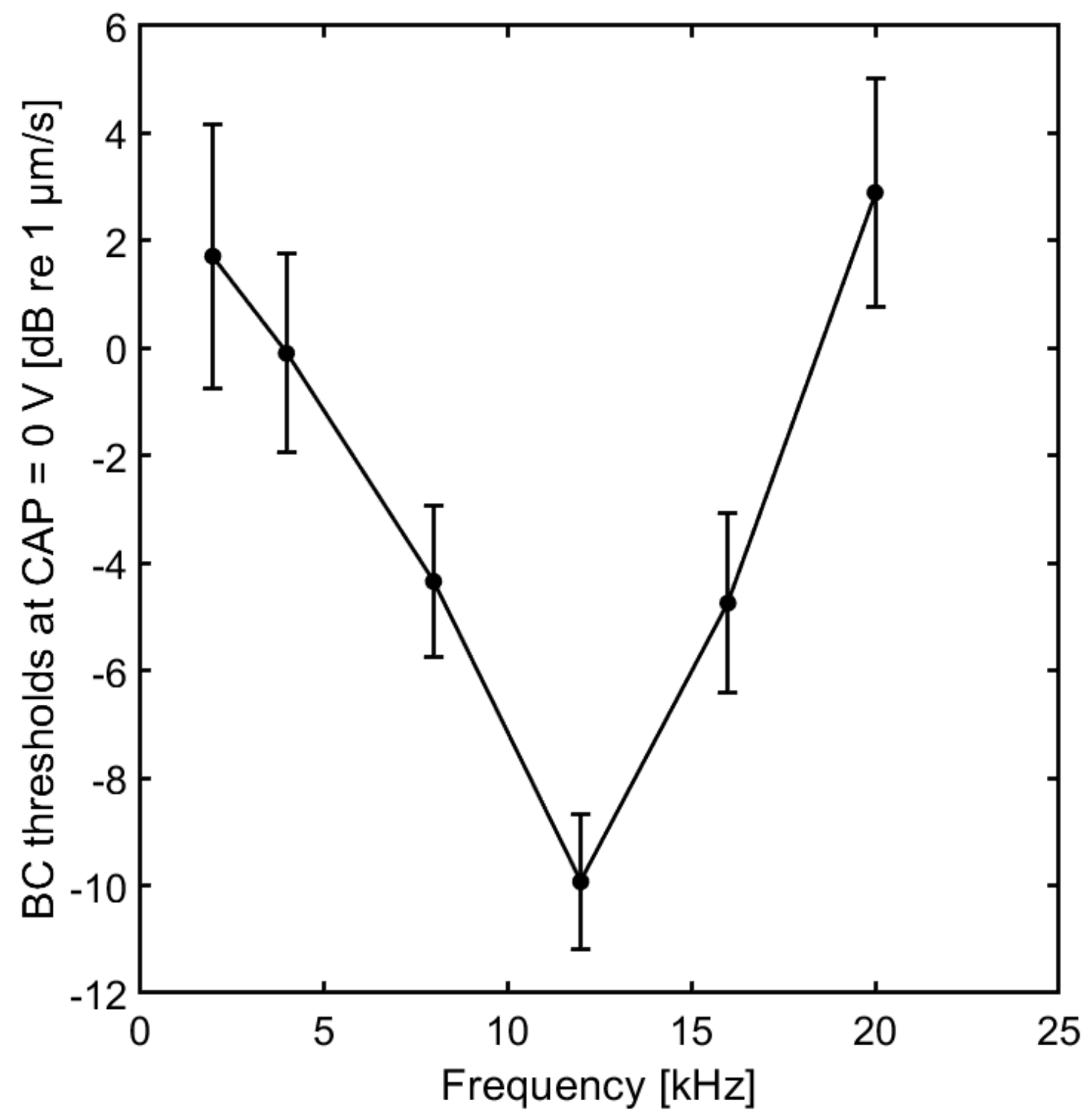

Figure 6a 


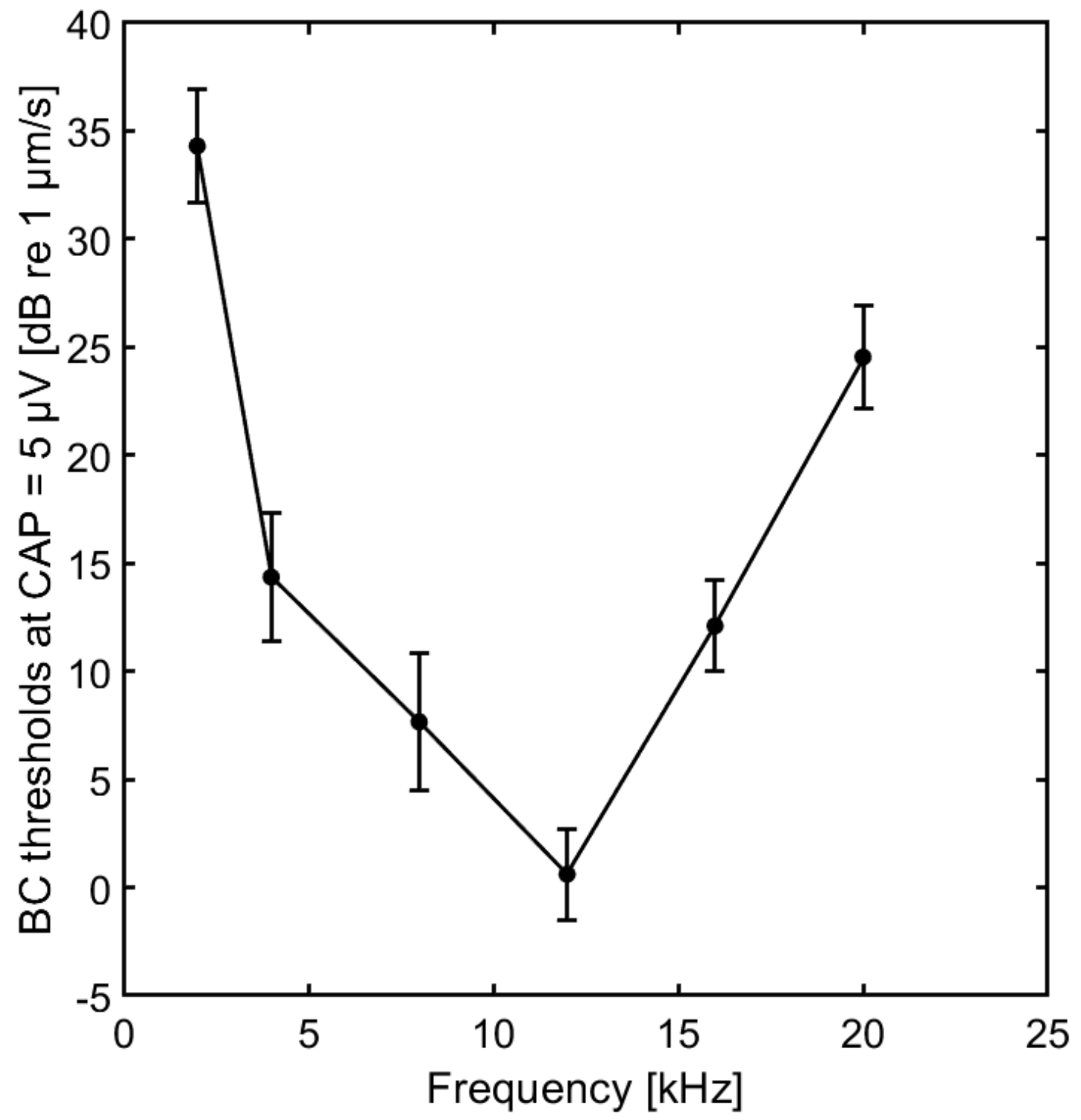

Figure 6b 


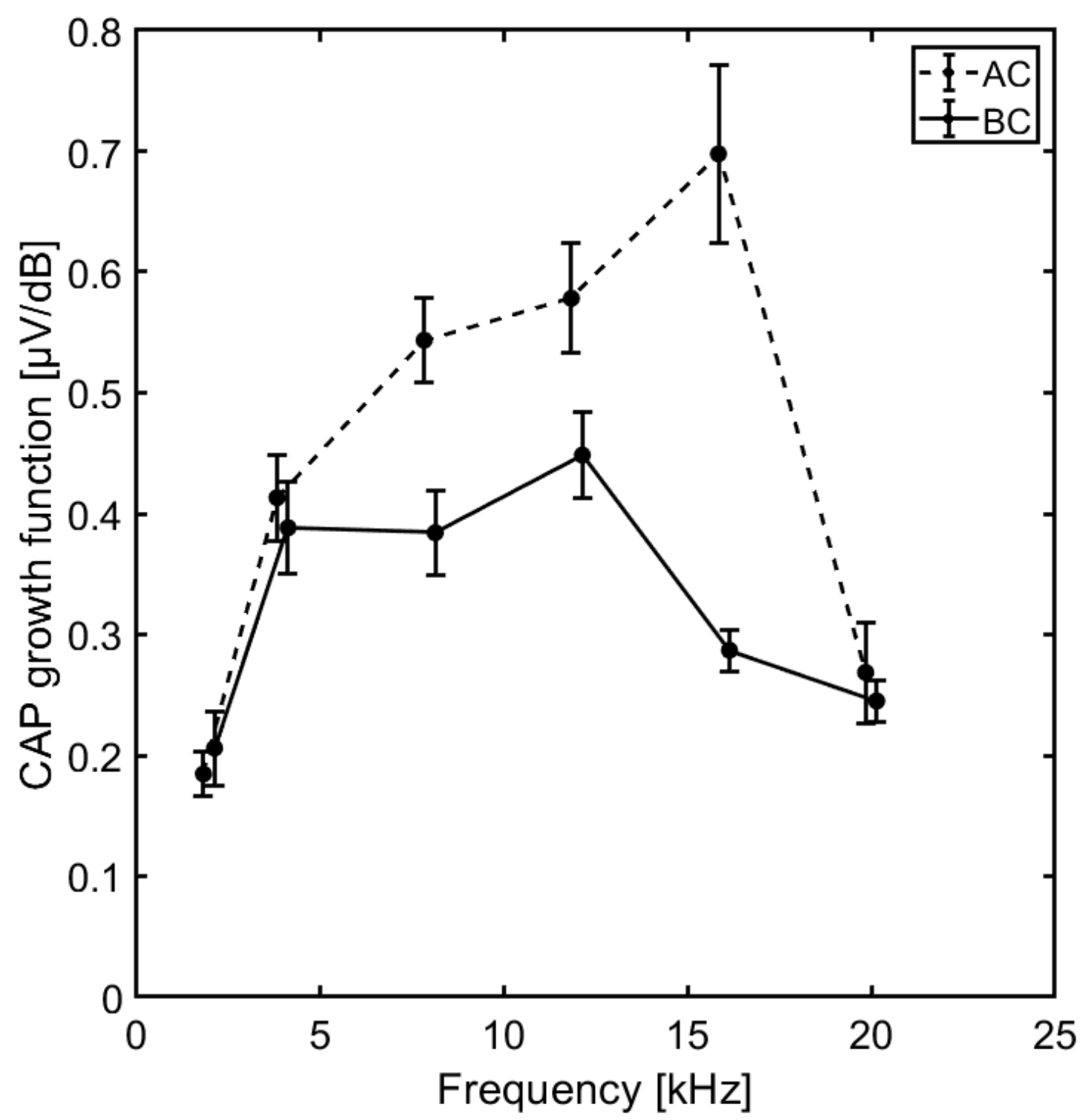

Figure 7 


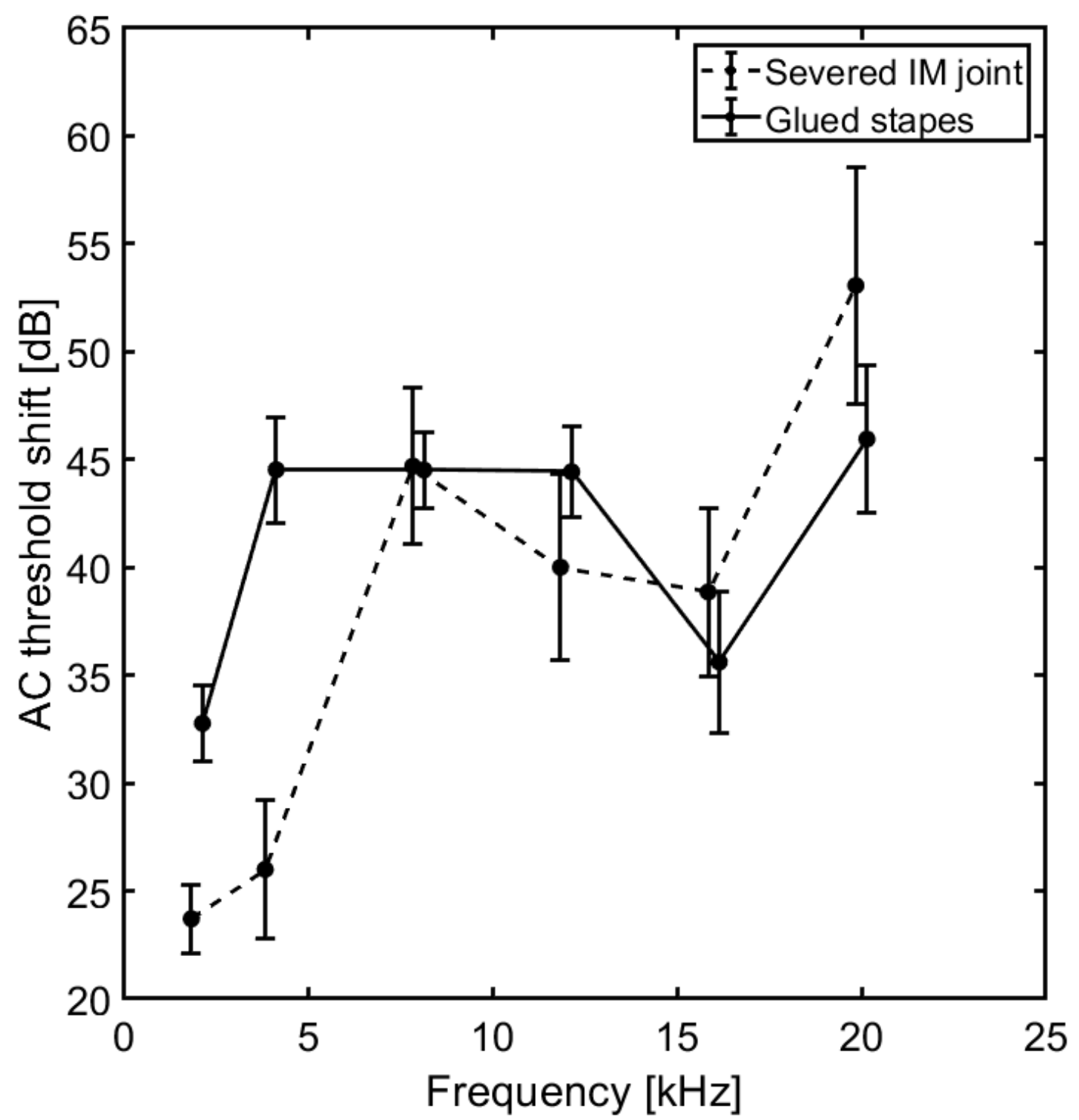

Figure 8a 


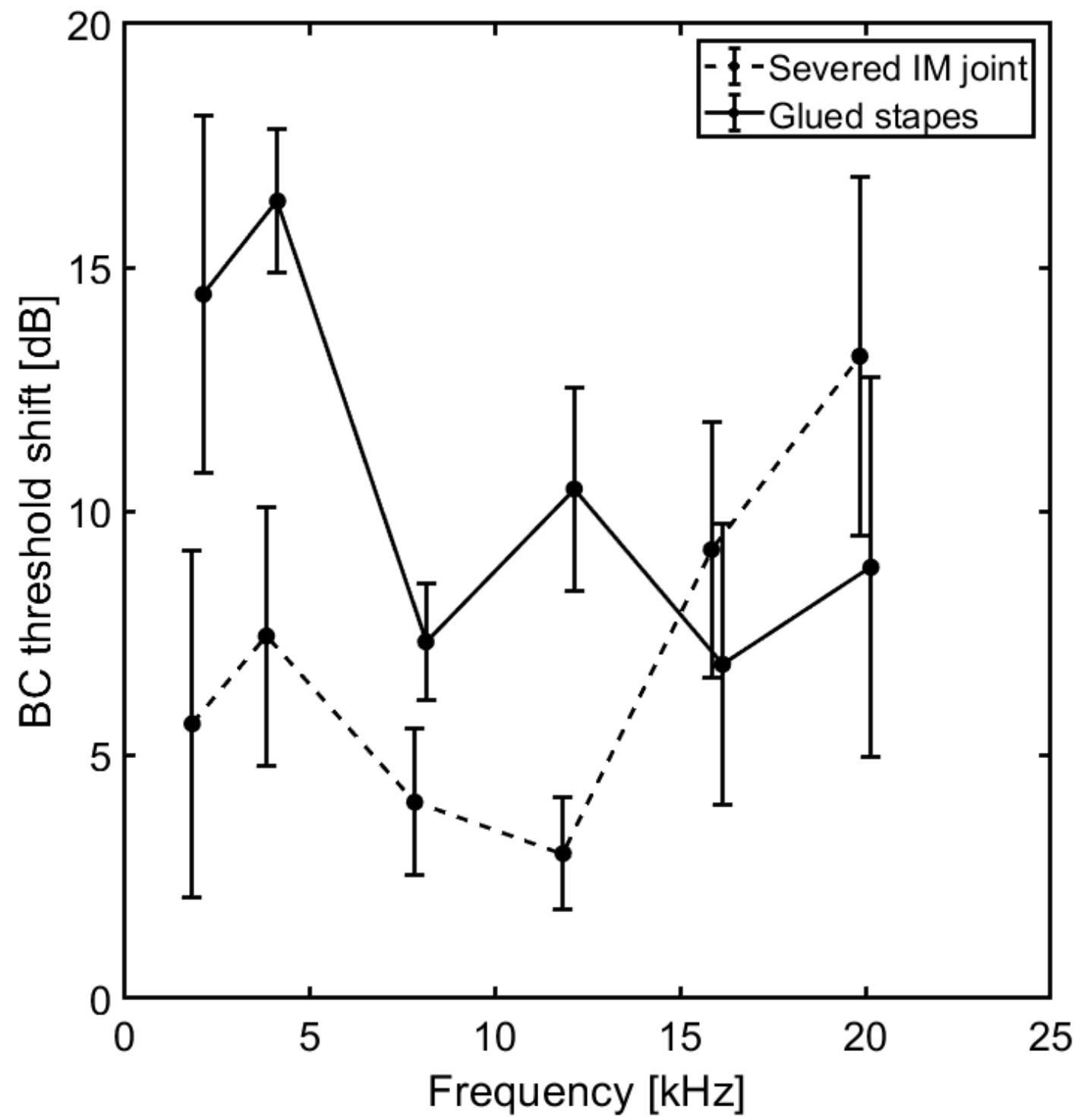

Figure $8 b$ 


\section{References}

Albuquerque, A. A. S., M. Rossato, J. A. A. de Oliveira and M. A. Hyppolito (2009). "Understanding the anatomy of ears from guinea pigs and rats and its use in basic otologic research." Brazilian Journal of Otorhinolaryngology 75(1): 43-49.

Bergin, M. J., P. A. Bird, S. M. Vlajkovic and P. R. Thorne (2015). "High frequency bone conduction auditory evoked potentials in the guinea pig: Assessing cochlear injury after ossicular chain manipulation." Hear Res 330(Pt A): 147-154.

Chen, R., M. Schwander, M. F. Barbe and M. M. Chan (2016). "Ossicular Bone Damage and Hearing Loss in Rheumatoid Arthritis: A Correlated Functional and High Resolution Morphometric Study in Collagen-Induced Arthritic Mice." PloS one 11(9): e0164078.

Crifo, S. (1973). "Shiver-audiometry in the conditioned guinea-pig (simplified Anderson-Wedenberg test)." Acta Otolaryngol 75(1): 38-44.

Curthoys, I. S., V. Vulovic, A. M. Burgess, L. Sokolic and S. C. Goonetilleke (2016). "The response of guinea pig primary utricular and saccular irregular neurons to bone-conducted vibration (BCV) and airconducted sound (ACS)." Hear Res 331: 131-143.

Dum, N., U. Schmidt and H. von Wedel (1980). "Age-dependence of the neural auditory thresholds of albino and pigmented guinea pigs." Arch Otorhinolaryngol 229(3-4): 191-199.

Eeg-Olofsson, M., S. Stenfelt, H. Taghavi, S. Reinfeldt, B. Hakansson, T. Tengstrand and C. Finizia (2013). "Transmission of bone conducted sound - correlation between hearing perception and cochlear vibration." Hear Res 306: 11-20.

Fridberger, A., J. Widengren and J. Boutet de Monvel (2004). "Measuring hearing organ vibration patterns with confocal microscopy and optical flow." Biophys J 86(1 Pt 1): 535-543.

Horner, K. C. and Y. Cazals (1990). "Alterations of CAP audiogram by increased endolymphatic pressure and its relation to hydrops." Hearing Research 45(1): 145-150.

Ingham, N. J., S. K. Thornton, S. D. Comis and D. J. Withington (1998). "The auditory brainstem response of aged guinea pigs." Acta Otolaryngol 118(5): 673-680.

Leggett K, M. V., Mulders WHAM (June 2018). "Divergent Responses in the Gap Prepulse Inhibition of the Acoustic Startle Reflex in Two Different Guinea Pig Colonies." The International Tinnitus Journal 22(1).

Liu, L., H. Wang, L. Shi, A. Almuklass, T. He, S. Aiken, M. Bance, S. Yin and J. Wang (2012). "Silent Damage of Noise on Cochlear Afferent Innervation in Guinea Pigs and the Impact on Temporal Processing." PLOS ONE 7(11): e49550.

Mori, T., K. Fujimura, M. Yoshida and H. Suzuki (2004). "Effects of glucocorticoid receptor antagonist on CAPs threshold shift due to short-term sound exposure in guinea pigs." Auris Nasus Larynx 31(4): 395-399.

Reis, A. d., S. P. Dalmolin and E. Dallegrave (2017). "Animal models for hearing evaluations: a literature review." Revista CEFAC 19(3): 417-428.

Snik, A. F., E. A. Mylanus and C. W. Cremers (2002). "The bone-anchored hearing aid in patients with a unilateral air-bone gap." Otol Neurotol 23(1): 61-66.

Stenfelt, S. (2011). "Acoustic and physiologic aspects of bone conduction hearing." Adv Otorhinolaryngol 71: 10-21.

Stenfelt, S. (2013). Bone Conduction and the Middle Ear.

Stenfelt, S. (2015). "Inner ear contribution to bone conduction hearing in the human." Hear Res 329: 41-51.

Stenfelt, S. (2016). "Model predictions for bone conduction perception in the human." Hear Res 340 : 135-143.

Stenfelt, S. and R. L. Goode (2005). "Transmission properties of bone conducted sound: measurements in cadaver heads." J Acoust Soc Am 118(4): 2373-2391.

Stenfelt, S., N. Hato and R. L. Goode (2002). "Factors contributing to bone conduction: the middle ear." J Acoust Soc Am 111(2): 947-959. 
Stenfelt, S., N. Hato and R. L. Goode (2004). "Fluid volume displacement at the oval and round windows with air and bone conduction stimulation." J Acoust Soc Am 115(2): 797-812.

Suits, G. W., R. E. Brummett and J. Nunley (1993). "Effect of otologic drill noise on ABR thresholds in a guinea pig model." Otolaryngol Head Neck Surg 109(4): 660-667. 